\title{
A comfortable and unconscious intubation by the combination of intermittent sevoflurane inhalation and the modified spray-as-you-go technique for a patient with severe postburn mentosternal contracture
}

\author{
Zhi Wang ${ }^{1}$, Yong Yang ${ }^{1}$, Yang Chen ${ }^{1}$, Bin Yi ${ }^{1}$, Kai Lu ${ }^{1}$, and Bing Chen ${ }^{2}$ \\ ${ }^{1}$ Southwest Hospital, Army Military Medical University \\ ${ }^{2}$ The Second Affiliated Hospital of Chongqing Medical University
}

August 14, 2021

\begin{abstract}
Airway management of patients with difficult airways is a challenge to the anesthesiologists and awake tracheal intubation is the recommended strategy. A safe, comfortable, unconscious, and satisfied intubation with spontaneous breathing keeping was achieved by intermittent sevoflurane inhalation and the modified spray-as-you-go technique for airway topicalization and intubation.
\end{abstract}

A comfortable and unconscious intubation by the combination of intermittent sevoflurane inhalation and the modified spray-as-you-go technique for a patient with severe postburn mentosternal contracture

Zhi Wang ${ }^{1}$, Yong Yang ${ }^{1}$, Yang Chen ${ }^{1}$, Bin $\mathrm{Yi}^{1}$, Kaizhi $\mathrm{Lu}^{1}$, Bing Chen ${ }^{2}$

${ }^{1}$ Department of Anesthesia, Southwest Hospital, Army Military Medical University, Chongqing 400038, China

${ }^{2}$ Department of Anesthesia, The Second Affiliated Hospital of Chongqing Medical University, Chongqing 400010, China

Corresponding author:Bing Chen (E-mail:chenbing2050@163.com), Department of Anesthesia, The Second Affiliated Hospital of Chongqing Medical University, Chongqing 400010, China, or Yong Yang (Email:yabg183@163.com), Department of Anesthesia, Southwest Hospital, Army Military Medical University, Chongqing 400038, China.

\section{Author contributions}

ZW, YY, and BC: study conception and design, acquisition, analysis, and interpretation of data, drafting and revising the article; YC, BY, KL: revising the article. All authors read and approved the final manuscript and agreed to be accountable for all aspects of the work.

\section{Key Clinical Message}

A safe and comfortable intubation with spontaneous breathing keeping was achieved in a patient with severe postburn mentosternal contracture and refused to accept awake intubation, which can be expanded to other patients with difficult airway. 


\begin{abstract}
Airway management of patients with difficult airways is a challenge to the anesthesiologists and awake tracheal intubation is the recommended strategy. A safe, comfortable, unconscious, and satisfied intubation with spontaneous breathing keeping was achieved by intermittent sevoflurane inhalation and the modified spray-as-you-go technique for airway topicalization and intubation.
\end{abstract}

Key words: Awake intubation, difficult airway, sevoflurane, spray-as-you-go.

\title{
Introduction
}

Airway management of patients with postburn mentosternal contracture is a challenge to the anesthesiologists $[1,2]$. Awake tracheal intubation (ATI) has been recommended as the gold standard in airway management for anticipated difficult airway [3]. However, ATI needs patients' cooperation and may leave a discomfort and nociceptive recall to patients, which leads to the rejection of ATI in the next surgery. We described a patient with severe post-burn contracture refused ATI due to the unsuccessful experience before, a comfortable and unconscious endotracheal intubation with spontaneous breathing keeping was achieved by the combination of intermittent sevoflurane inhalation and the modified spray-as-you-go (SAYGO) technique using flexible bronchoscopy.

\section{Case Presentation}

A 33-year-old woman, with severe postburn mentosternal contracture and cicatricial carcinoma, presented for skin grafting surgery in our hospital. The burn occurred when she was 4-year-old. She underwent two reconstructive procedures at 7 and 14 years in local medical centers. Due to the pain caused by the expansion of cicatricial carcinoma, affecting eating and speaking, she had tried several medical centers for treatment in the past year, but failed for unsuccessful ATI. In preoperative physical examination, severe scar contractures and a great tumor of approximately $15 \mathrm{~cm} \times 12 \mathrm{~cm}$ were observed on the lower lip, neck, and anterior chest (Fig. 1a and 1b); the chin, chest, and bilateral armpits fused together; the cervicomental and mentosternal angles completely obliterated; the anterior neck structures, including the larynx, the trachea, and the carotid arteries, were unidentifiable or impalpable. Mouth opening was limited (15 mm) and Mallampati test was unavailable. The left nostril was obstructive for stenosis, but the right nostril breathing was smooth. Preoperative X-rays and a computed tomography scan (data not shown) revealed distortion of the upper airway and no stenosis of the trachea. It was difficult to perform face mask ventilation because of the nearly fixed neck and regressed mandible. Meanwhile, conventional laryngoscopic intubation, laryngeal mask airway, lightwand, or a GlideScope Video laryngoscope were thought to be impossible. Moreover, surgical tracheostomy under local anesthesia [4] was not the preferred strategy for the existence of tumor on neck. Furthermore, the patient rejected ATI for discomfort and nociceptive recall before. Therefore, orotracheal or right nasotracheal fiberoptic intubation with sedation seems the last remaining strategy. Here we used intermittent sevoflurane inhalation for short sedation and modified SAYGO technique using flexible bronchoscopy for airway topicalization and nasotracheal intubation.

A written anesthetic consent was taken with explanation focused on the risks of difficult airway. Atropine 0.5 $\mathrm{mg}$ was intramuscular injected to reduce secretion before transferring to the operating room. The patient was monitored and preoxygenated once she arrived in the operation room. Vital signs were stable. A pillow and some folded sheets were stuffed between the patient back and the operating bed to make her feel comfortable. Intravenous midazolam $2 \mathrm{mg}$ and sufentanil $5 \mu \mathrm{g}$ were given. Nasal passage was anesthetized by pledgets with $2 \%$ lidocaine and $0.25 \%$ phenylephrine. Sevoflurane $2 \%$ with a flow rate of $4 \mathrm{~L} / \mathrm{min}$ with $100 \% \mathrm{O}_{2}$, was administered via an oxygen mask connected to the Y-piece of the ventilator circuit. The concentration of sevoflurane was gradually increased to $4 \%$ [5] and stopped when the bispectral index reached 55-60 within 3 minutes, then airway reassessment and topicalization were achieved by the modified SAYGO technique [6-8]. An epidural catheter (Fig. 2), with an outer diameter of $3.8 \mathrm{~mm}$, was fixed and $1.5 \mathrm{~cm}$ longer was applied at the end of the fiberscope (MDH A10; Zhuhai Mindhao Medical Technology Co., Ltd., ShenZhen, China). Topicalization was achieved by spraying $2 \%$ lidocaine $(7 \mathrm{ml})$ via the catheter onto the posterior nasal canal, pharyngeal cavity, epiglottis, glottis, and tracheal (Fig. 3). Meanwhile, supplemental oxygen 10 
L/min was delivered by a hose (Fig. 2a) through the mouth to avoid hypoxemia. When lidocaine worked, about 5 minutes later, sevoflurane was inhaled again until the bispectral index reached 55-60. Then, a Parker Flex-Tip @ tube with an inner diameter of $6.0 \mathrm{~mm}$ (Lead Medical Instrument Co., Ltd., Guangzhou, China), which was heated by 40 and lubricated in advance, was successfully and smoothly inserted into the trachea from the direction of flexible bronchoscopy (Fig. 1c). No stress reactions, including cough, hypertension, tachycardia, arrhythmia, hypoxia, and bronchospasm, and no intubation related complications, such as airway trauma, airway obstruction, and bleeding, were occurred during intubation. Importantly, the patient was very satisfied with this experience after emergence.

\section{Discussion}

General recommendations for difficult airway management are awake fiberoptic intubation, awake video laryngoscope, laryngeal mask airway as an intubating conduit, lightwand, oral or nasal blind intubation, retrograde intubation, invasive airway access, and ECMO which is left as the last method [9]. In this case, due to the severe contractures and microstomia, direct visualization of the pharynx and larynx by video laryngoscope seemed impossible. Laryngeal mask airway was not considered because size \# 3 or 4 for a female adult is too large to pass through her mouth. Orotracheal intubation with lightwand was excluded on the reason that neck scars cannot be illuminated. Retrograde intubation and tracheostomy were also excluded for the reason that anterior neck structures, including the larynx, trachea, and carotid arteries, are unidentifiable and impalpable. For the distortion of the upper airway and uncertainty of success, oral or nasal blind intubation was not the preferred choice. Due to a good safety and success profile, awake fiberoptic intubation is a preferred choice of anticipated difficult tracheal intubation [3]. However, ATI may give patients significant discomfort and nociceptive recall [10-12] or be perceived as potentially dangerous when causing a pronounced sympathetic response [13]. Furthermore, due to the several failures of awake intubation in other medical centers, the patient refused to accept it again. Therefore, fiberoptic intubation with precise sedation, analgesia, and without inhibition of spontaneous ventilation and cardiovascular function seems an ideal choice.

At present, many sedative drugs, such as midazolam, dexmedetomidine, propofol, sevoflurane, can be selected. A low dose of midazolam produces a direct amnesia effect. Dexmedetomidine provides a good sedative effect in awake conditions, but the sedation needs to be carefully titrated as excessive sedation can lead to hypoventilation and bradycardia, or inadequate sedation leads to discomfort, anxiety and excessive sympathetic discharge. Moreover, dexmedetomidine may cause nociceptive recall $[8,14]$. Compared with propofol intravenous anesthesia, sevoflurane inhalational has less effect on respiratory depression [13]. Moreover, sevoflurane can be quickly washed out. Thus, it is more controllable than other intravenous drugs. In this case, midazolam $2 \mathrm{mg}$, sufentanil $5 \mu \mathrm{g}$, and intermittent sevoflurane inhalation were administrated to provide precise sedation and analgesia. Meanwhile, an oral hose was connected to a high flow of oxygen to prevent hypoxia. However, sedation should not be used as a substitute for inadequate airway topicalization [3].

To sufficiently anesthetize the upper airway and suppress the gag, swallow and cough reflexes, a perfect topicalization is essential. There are many ways of airway topicalization, such as nebulization with lidocaine, nerve block, thyrocricocentesis spraying, and the SAYGO technique [2]. However, research indicated that atomization of local anesthetics had a potential possibility of higher stress responses and poisoning [15]. Due to anatomical structure changes, nerve block and thyrocricocentesis were impossible for such kind of patients. Compared with the classical SAYGO technique that lidocaine sprayed directly via the working channel of the fiberscope, the modified SAYGO technique, which lidocaine sprayed via an epidural catheter inserted through the working channel of the fiberscope, controls the dosage of local anesthetics more accurately and does a better anesthesia effect, therefore usually used in patients with difficult airway [6-8]. However, the epidural catheter does not match with all fiberscopes. Here, we directly fastened the epidural catheter at the end of the fiberscope. Moreover, this SAYGO technique can evaluate the airway passage directly, which increases the safety of intubation. Thus, it seemed a better choice in this case.

Furthermore, once the local anesthetics worked, the patient was sedated by sevoflurane inhalation again, 
then intubated by the guidance of flexible bronchoscopy. Taken together, using intermittent sevoflurane inhalation and the modified SAYGO technique, a safe, comfortable, unconscious, and satisfied intubation with spontaneous breathing keeping was achieved in a postburn patient with severe difficult airway and unwillingness to accept ATI. Moreover, this strategy is not limit to postburn patients with difficult airway.

\section{Conclusion}

This case demonstrated the combination of intermittent sevoflurane inhalation and the modified SAYGO technique could provide a safe, comfortable, unconscious, and satisfied airway management with spontaneous breathing keeping for patients with anticipated difficult airway, such as severe postburn mentosternal scar contracture, and/or unwillingness to accept ATI.

\section{Data Availability}

No data were used during the study.

\section{Conflicts of Interest}

None

\section{Funding Statement}

This work is supported by the Kuanren Talents Program of the Second Affiliated Hospital of Chongqing Medical University.

\section{References}

1. Caruso TJ, Janik LS, Fuzaylov G. Airway management of recovered pediatric patients with severe head and neck burns: a review. Paediatr Anaesth. 2012;22(5):462-8.

2. Prakash S, Mullick P. Airway management in patients with burn contractures of the neck. Burns. $2015 ; 41(8): 1627-35$.

3. Ahmad I, El-Boghdadly K, Bhagrath R, Hodzovic I, McNarry AF, Mir F, O'Sullivan EP, Patel A, Stacey M, Vaughan D. Difficult Airway Society guidelines for awake tracheal intubation (ATI) in adults. Anaesthesia. 2020;75(4):509-28.

4. Park CD, Lee HK, Yim JY, Kang IH. Anesthetic management for a patient with severe mento-sternal contracture: difficult airway and scarce venous access -A case report. Korean J Anesthesiol. 2013;64(1):61-4.

5. Smith CE, Fallon WF, Jr. Sevoflurane mask anesthesia for urgent tracheostomy in an uncooperative trauma patient with a difficult airway. Can J Anaesth. 2000;47(3):242-5.

6. Siddiqui N, Arzola C, Friedman Z, Guerina L, You-Ten KE. Ultrasound Improves Cricothyrotomy Success in Cadavers with Poorly Defined Neck Anatomy: A Randomized Control Trial. Anesthesiology. 2015;123(5):1033-41.

7. Rosenstock CV, Thogersen B, Afshari A, Christensen AL, Eriksen C, Gatke MR. Awake fiberoptic or awake video laryngoscopic tracheal intubation in patients with anticipated difficult airway management: a randomized clinical trial. Anesthesiology. 2012;116(6):1210-6.

8. Liu HH, Zhou T, Wei JQ, Ma WH. Comparison between remifentanil and dexmedetomidine for sedation during modified awake fiberoptic intubation. Exp Ther Med. 2015;9(4):1259-64.

9. Apfelbaum JL, Hagberg CA, Caplan RA, Blitt CD, Connis RT, Nickinovich DG, Benumof JL, Berry FA, Bode RH, Cheney FW, Guidry OF, Ovassapian A. Practice guidelines for management of the difficult airway: an updated report by the American Society of Anesthesiologists Task Force on Management of the Difficult Airway. Anesthesiology. 2013;118(2):251-70. 
10. Law JA, Morris IR, Brousseau PA, de la Ronde S, Milne AD. The incidence, success rate, and complications of awake tracheal intubation in 1,554 patients over 12 years: an historical cohort study. Can J Anaesth. 2015;62(7):736-44.

11. Fiadjoe JE, Nishisaki A, Jagannathan N, Hunyady AI, Greenberg RS, Reynolds PI, Matuszczak ME, Rehman MA, Polaner DM, Szmuk P, Nadkarni VM, McGowan FX, Jr., Litman RS, Kovatsis PG. Airway management complications in children with difficult tracheal intubation from the Pediatric Difficult Intubation (PeDI) registry: a prospective cohort analysis. Lancet Respir Med. 2016;4(1):37-48.

12. Joseph TT, Gal JS, DeMaria S, Jr., Lin HM, Levine AI, Hyman JB. A Retrospective Study of Success, Failure, and Time Needed to Perform Awake Intubation. Anesthesiology. 2016;125(1):105-14.

13. Xue FS, Yuan YJ, Wang Q, Liu JH, Liao X. Comments on "Propofol versus sevoflurane for fiberoptic intubation under spontaneous breathing anesthesia in patients difficult to intubate". Minerva Anestesiol. 2011;77(4):470-1; author reply 472-3.

14. Cattano D, Lam NC, Ferrario L, Seitan C, Vahdat K, Wilcox DW, Hagberg CA. Dexmedetomidine versus Remifentanil for Sedation during Awake Fiberoptic Intubation. Anesthesiol Res Pract. 2012;2012:753107.

15. Gupta B, Kohli S, Farooque K, Jalwal G, Gupta D, Sinha S, Chandralekha. Topical airway anesthesia for awake fiberoptic intubation: Comparison between airway nerve blocks and nebulized lignocaine by ultrasonic nebulizer. 1. Caruso TJ, Janik LS, Fuzaylov G. Airway management of recovered pediatric patients with severe head and neck burns: a review. Paediatr Anaesth 2012; 22: 462-8.

2. Prakash S, Mullick P. Airway management in patients with burn contractures of the neck. Burns 2015; 41: $1627-35$.

3. Ahmad I, El-Boghdadly K, Bhagrath R, Hodzovic I, McNarry AF, Mir F, O'Sullivan EP, Patel A, Stacey M, Vaughan D. Difficult Airway Society guidelines for awake tracheal intubation (ATI) in adults. Anaesthesia.2020 $04 ; 75(4): 509-528$.

4. Park CD, Lee HK, Yim JY, Kang IH. Anesthetic management for a patient with severe mento-sternal contracture: difficult airway and scarce venous access -A case report. Korean J Anesthesiol 2013; 64: 61-4.

5. Smith CE, Fallon WF, Jr. Sevoflurane mask anesthesia for urgent tracheostomy in an uncooperative trauma patient with a difficult airway. Can J Anaesth 2000; 47: 242-5.

6. Siddiqui N, Arzola C, Friedman Z, Guerina L, You-Ten KE. Ultrasound Improves Cricothyrotomy Success in Cadavers with Poorly Defined Neck Anatomy: A Randomized Control Trial. Anesthesiology 2015; 123: 1033-41.

7. Rosenstock CV, Thogersen B, Afshari A, Christensen AL, Eriksen C, Gatke MR. Awake fiberoptic or awake video laryngoscopic tracheal intubation in patients with anticipated difficult airway management: a randomized clinical trial. Anesthesiology 2012; 116: 1210-6.

8. Liu HH, Zhou T, Wei JQ, Ma WH. Comparison between remifentanil and dexmedetomidine for sedation during modified awake fiberoptic intubation. Exp Ther Med 2015; 9: 1259-64.

9. Apfelbaum JL, Hagberg CA, Caplan RA, Blitt CD, Connis RT, Nickinovich DG, Benumof JL, Berry FA, Bode RH, Cheney FW, Guidry OF, Ovassapian A. Practice guidelines for management of the difficult airway: an updated report by the American Society of Anesthesiologists Task Force on Management of the Difficult Airway. Anesthesiology 2013; 118: 251-70.

10. Law JA, Morris IR, Brousseau PA, de la Ronde S, Milne AD. The incidence, success rate, and complications of awake tracheal intubation in 1,554 patients over 12 years: an historical cohort study. Can J Anaesth 2015; 62: 736-44.

11. Fiadjoe JE, Nishisaki A, Jagannathan N, Hunyady AI, Greenberg RS, Reynolds PI, Matuszczak ME, Rehman MA, Polaner DM, Szmuk P, Nadkarni VM, McGowan FX, Jr., Litman RS, Kovatsis PG. Air- 
way management complications in children with difficult tracheal intubation from the Pediatric Difficult Intubation (PeDI) registry: a prospective cohort analysis. Lancet Respir Med 2016; 4: 37-48.

12. Joseph TT, Gal JS, DeMaria S, Jr., Lin HM, Levine AI, Hyman JB. A Retrospective Study of Success, Failure, and Time Needed to Perform Awake Intubation. Anesthesiology 2016; 125: 105-14.

13. Xue FS, Yuan YJ, Wang Q, Liu JH, Liao X. Comments on "Propofol versus sevoflurane for fiberoptic intubation under spontaneous breathing anesthesia in patients difficult to intubate". Minerva Anestesiol 2011; 77: 470-1; author reply 72-3.

14. Cattano D, Lam NC, Ferrario L, Seitan C, Vahdat K, Wilcox DW, Hagberg CA. Dexmedetomidine versus Remifentanil for Sedation during Awake Fiberoptic Intubation. Anesthesiol Res Pract 2012; 2012: 753107.

15. Gupta B, Kohli S, Farooque K, Jalwal G, Gupta D, Sinha S, Chandralekha. Topical airway anesthesia for awake fiberoptic intubation: Comparison between airway nerve blocks and nebulized lignocaine by ultrasonic nebulizer. Saudi J Anaesth. 2014;8(Suppl 1):S15-9.

Fig. 1. The face, neck, and chest appearance of a 33-year-old woman with severe postburn mentosternal contracture. Views on the front (a) and lateral (b) showed obvious contractures and a large carcinoma on the face, neck, and chest, and a small oral opening. (c) Intubated state after skin grafting surgery.

Fig. 2. The modified spray-as-you-go technique. (a) An epidural catheter was fixed at the end of the fiberscope. Supplemental oxygen was delivered via a tube through the mouth to avoid hypoxemia. Views on the lateral (b) and top (c) showed the local anesthetic was sprayed out from the epidural catheter.

Fig. 3. Images showed the anesthesiologist sprayed $2 \%$ lidocaine via an epidural catheter onto the patient's airway mucosa. (a) Posterior nasal canal, (b) left pharyngeal recess, (c) epiglottis, (d) right pharyngeal recess, (e) supraglottis, (f) subglottis and trachea.
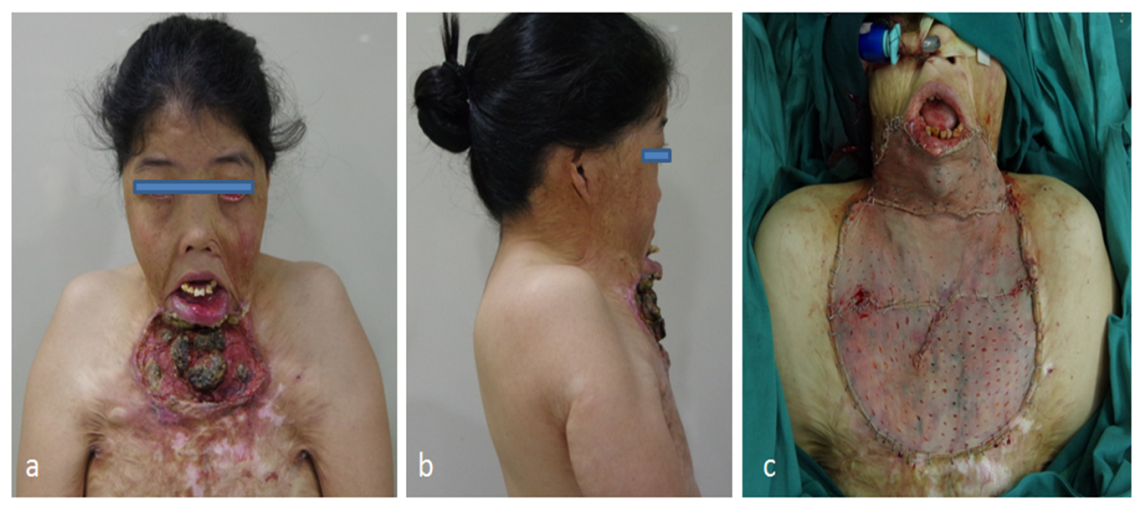

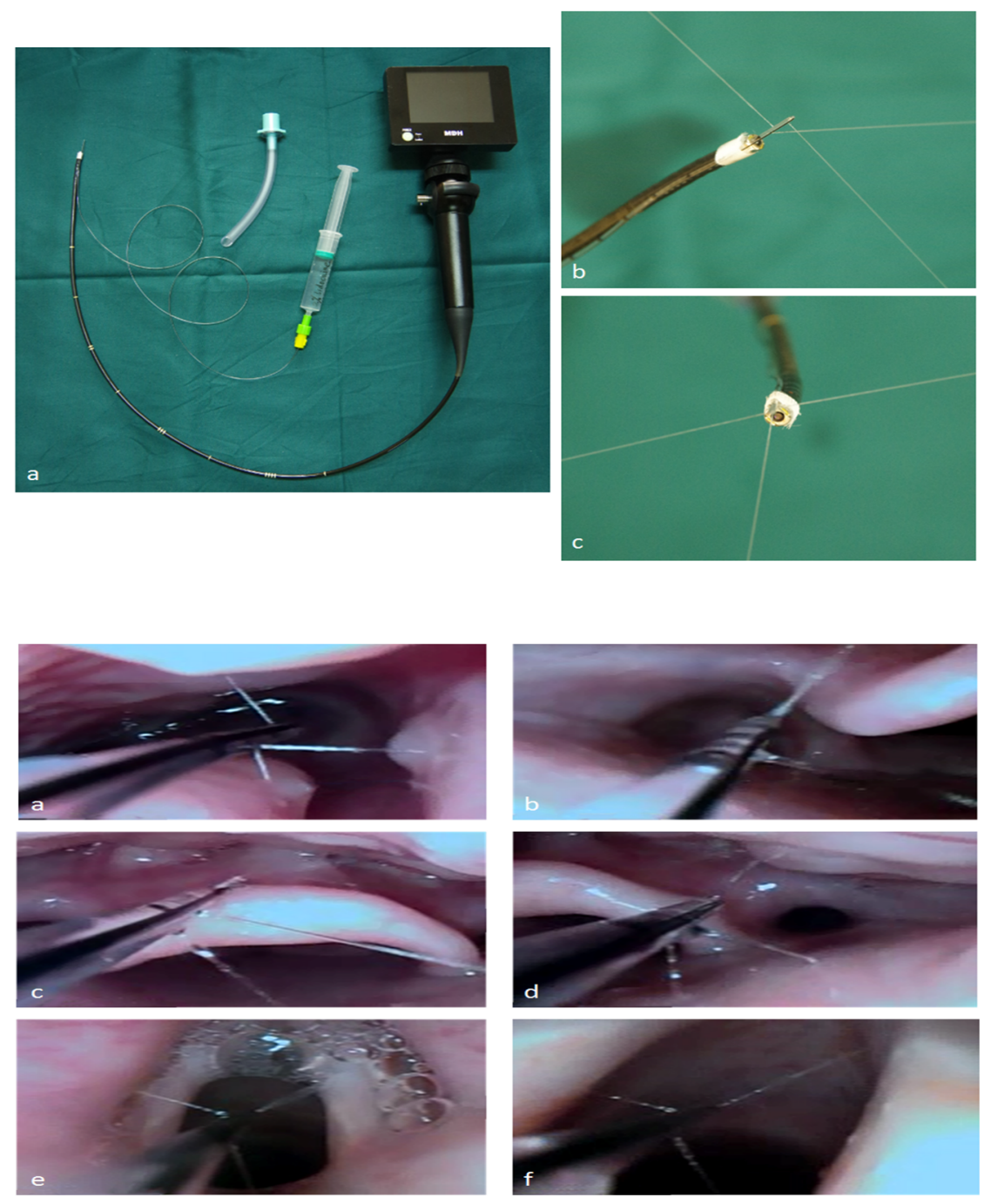